\title{
An Experimental Study on the Inner and Outer Glass Cover Temperatures of Solar Still
}

\author{
Pankaj K. srivastava ${ }^{1}$, AshutoshDwivedi ${ }^{2}$, Mihir Kumar Pandey ${ }^{3}$, Abhay Agrawal ${ }^{4}$ and R.S. Rana ${ }^{5}$ \\ ${ }^{1}$ Mechanical Engineering Department, Rewa Engineering College, Rewa (M.P.), India \\ ${ }^{2}$ Mechanical Engineering Department, Vindhya Institute of Technology and Science, Satna (M.P.), India \\ ${ }^{3}$ Mechanical Engineering Department, Jai Narayan College of Technology, Rewa (M.P.), India \\ ${ }^{4}$ Mechanical Engineering Department, Rewa Engineering College, Rewa (M.P.), India \\ ${ }^{5}$ Mechanical EngineeringDepartmen, tMaulana Azad National Institute of Technology, Bhopal (M.P.) India
}

\begin{abstract}
The glass cover of a solar still plays a major role in its performance andefficiency since the output depends directly on the water and glass cover temperature difference. In most of the experimental studies, the outer glass cover temperatureswererecorded and considered as the glass cover temperature for calculations, however the condensation on the glass cover surface dependsmore on the inner surface temperature than the outer. An experimental study was conducted in order to study the difference between the inner and the outer glass cover temperature difference in a conventional basin type solar still and a low thermal inertia solar still obtained by modifying the conventional still. It was observed that for theconventional still, the temperature difference was maximum upto $7.14 \%$ at noon and insignificant in the morning and evening hours. For the low thermal inertia still, the difference was more upto $10.2 \%$ at around 11:00 hrs and zero during the early morning and the evening hours. A significant difference in the glass cover temperature curves for the two different types of solar stills can be seen
\end{abstract}

\section{Introduction}

In most of the remote and rural regions of the world.electric power supply and potable water availability has always been a major problem and urgent necessity of the natives. To cope with such problems, equipments and devices which do not require electricity for converting brakish or saline water into potable or drinking water are desired. Solar stills are simple devices which can provide potable water by using the thermal energy of the sun.Despite of being simpleand economical in construction and working, solar stills suffer from a poor thermal efficiency and hence low distillate output.

A lot of research work has been conducted by several researchers on solar stills all over the world. Heat and mass transfer relations were developed by Dunkle [1]. For given ambient and basin water temperatures, the glass cover temperature could be calculated by trial and error method. The performance of a solar still improves with the reduced air gap, which is due to the fact that, at reduced air gap, the vapor length is small and the still can operate by diffusion mass transfer as investigated by Sodha et al. [2]. Furthermore, due to reduced mass the air gets saturated more quickly. Sharma and Mullick [3] developed an empirical relation for the calculation of glass cover temperature with the help of which the heat transfer coefficients, upward heat flow and the evaporation in a solar still could be estimated.
It was established by Tiwari et al. [4] that the inclination of the still cover and the direction of its inclination depend upon the latitude of the location. Besides, in case of the cover angle equal to the latitude of the location, the sun rays are received by the still nearly normal throughout the year. It was also investigated that the cover temperature significantly affects the productivity of the solar still. A decrease in the cover temperature increases the productivity of the still, since a larger cover and basin water temperature difference increases both the convective and evaporative heat transfer in the solar still. Minasian and Al-Karaghouli [5] developed a wick-basin type solar still with improved productivity. An experimental study was conducted by Madani and Zaki [6] on the solar still with porous basin and an improvement in the performance was observed. A.A. El-Sebaii [7] investigated that the higher wind velocity increases the convective heat transfer from cover to atmosphere, which in turn increases the rate of condensation and evaporation, thus increasing the productivity. Bassam et al. [8] conducted an experimental study by placing sponge cubes on basin water and obtained an increase in the productivity. Karaghouli and Alnaser [9] conducted an experimental study to compare the performance of single and double slope solar stills. Shukla and Sorayan [10] developed a mathematical model based on regression analysis to determine the values $\mathrm{C}$ and $\mathrm{n}$ with the help of the experimental data. Expressions for internal heat transfer coefficients were 
determined by using both inner and outer glass cover temperatures. Expressions for water and glass temperatures, hourly yield and instantaneous efficiency for double slope distillation systems were derived by Shukla and Rai [11]. In this analysis a thermal model was developed to predict the performance of the solar still based on the inner and outer glass cover temperatures.

Kabeel et al [12] conducted an experimental study in Kafrelsheikh, Egypt in which two types of solar distillation systems were tested. It was observed that the stepped solar still gave higher distillate production than the conventional still. For $5 \mathrm{~mm}$ water depth about $57 \%$ higher output was obtained in the stepped still. Srivastava and Agrawal [13] conducted an experimental and theoretical analysis of a basin type solar still with multiple floating porous absorbers. They obtained an increase in the distillate output by around $68 \%$ over the conventional basin type solar still. Srivastava and Agrawal [14] developed an extended porous fin type still by placing jute cloth porous fins in the basin water in such a way that the fins were partially dipped and partially extended above the basin water surface. The performance of the improved still in the winter and summer season has been reported. An appreciable improvement in the productivity along with nocturnal production was observed due to porous fins. Srivastava and Agrawal [15] conducted an experimental study on the floating absorber type solar still and observed a highest of $74.6 \%$ more output in the month of January and lowest $35.5 \%$ more in August as compared to that of the conventional still.BadushaanfArjunan [16] usedcomputationalFluid Dynamics (CFD) method, to develop a two phase threedimensionalmodel for simulation of a solarstill. Simulation resultwerecomparedwithactualexperimental data of solarstill. A good agreement wasfoundbetweenexperimental data and CFD data of fresh water productivity, water temperature and heattransfer coefficients. Kumar and Tiwari [17] estimated convective heat transfer in a solar distillation system.Hijleh [18] performed water film cooling of the glass cover and obtained an increase in the performance of the solar still. Sebaiiet. Al. [19] investigated the effect of wind speed on some designs of solar stills. Velmuruganet. Al. [20] experimented by integrating fins on the basin plate with the help of which they achieved an increase in the distillate production in the solar still. Tanaka [21] conducted experimental study with internal and external reflecters. It was observed that a slight inclination of the relector in the winter season gave an increase in the distillate yield by 70 to 80 percent. Eldalil and Khalid [22] applied vibratory harmonic effect to a basin type solar still. A productivity increase upto $5,851 / \mathrm{m}^{2}$ and average daily efficiency of $60 \%$ was observed. Samee et. al. [23] conductedan study on the design and performance of a solar still.

In the present work, an experimental study on solar still glass cover temperatures conducted during the winter season in central Indian location is presented.

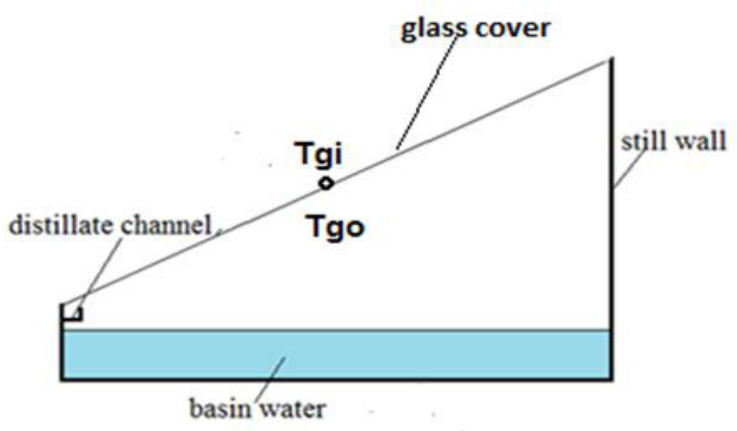

Figure 1.Conventional basin type solar still.

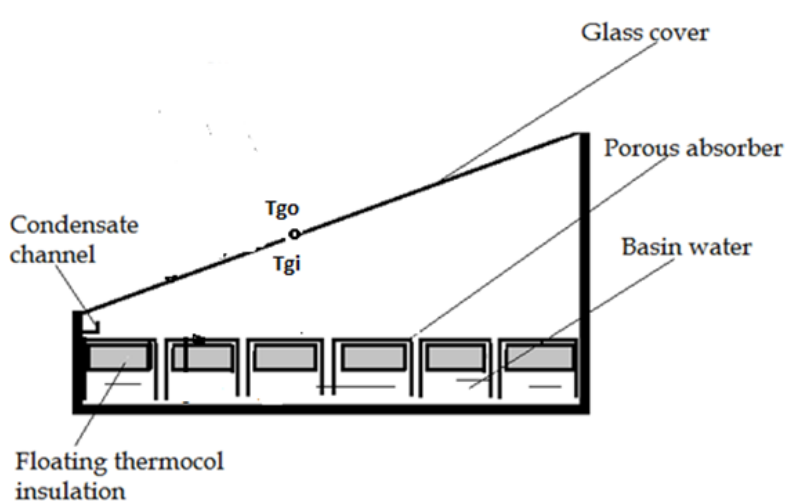

insulation

Figure 2. Low thermal inertia solar still.

\section{Experimental procedure}

The experimental study was conducted during the winter month of November in a Central Indian location. The experimental setup consisted of two identical single sloped basin type solar stills made of wood with effective basin area of $0.5 \mathrm{~m}^{2}$ each. One of the stills was modified into low thermal inertia solar still by floating blackened jute cloth absorbers with the help of $20 \mathrm{~mm}$ thick thermocol planks on the basin water. The $4 \mathrm{~mm}$ thick glass covers in both the stills were kept at an angle of $25^{\circ}$ which is nearly equal to the latitude of the place of experimental study. Beside, at the cover angle equal to that of the latitude of the place, the solar still receives the solar radiation nearly perpendicular to it all round the year.The basin water level in the two stills was kept as $50 \mathrm{~mm}$. Vapour tightness of the glass covers was ensured by applying rubber lining at the glass edges. Thermocouple wires for recording the inner and outer glass cover temperaturesTgi and Tgorespectively were attached on the lower and upper sides respectively at the centres of each glass covers. The multi-point digital temperature indicator gave the temperatures of all the desired points for both the solar stills.

The experiments were conducted from 08:00 hrs to 17:00 hours every day for five consecutive days. The temperatures were recorded at hourly intervals. The water level in the stills was kept constant at $50 \mathrm{~mm}$ by topping up the basin water at regular intervals. The best observations of the five days experimentation are presented. 


\section{Thermal relations}

The amount of distillate per hour per square metrefor the solar still can be obtained from the relation,

$$
m_{w}=\frac{q_{e w g}}{h_{f g}}
$$

In the equation no. (1) qewg is the evaporative heat transfer from the water surface to the glass cover inner surface and $\mathrm{h}_{\mathrm{fg}}$ is the latent heat of vaporization of water.

The evaporative heat transfer is given as

$$
q_{e w g}=h_{e w g}\left(T_{w}-\mathrm{T}_{\mathrm{g}}\right)
$$

Where $h_{\text {ewg }}$ is the evaporative heat transfer coefficient as per Dunkle [1], Tw and Tg are the water surface and glass cover temperatures.

The evaporative heat transfer coefficient between the water surface and the glass cover depends upon the convective heat transfer and hence it is given as,

$$
h_{e w g}=\frac{0.01623 * h_{c w g}\left(P_{w}-P_{g}\right)}{\left(T_{w}-T_{g}\right)}
$$

The convective heattransfer coefficient isdependentupon the difference in the water and the glass covertemperatures and the partial pressures at the temperaturesof the water and glass cover surface.Henceitisrepresentedas,

$$
h_{c w g}=0.884\left[\left(T_{w}-T_{g}\right)+\frac{\left(P_{w}-P_{g}\right) T_{w}}{\left(268.9 * 10^{3}-P_{w}\right)}\right]^{1 / 3}
$$

In the above equation $P_{w}$ and $P_{g}$ are the partial presures at water and glass cover temperatures respectively.

\section{Results and discussion}

Fig. 3 shows the hourly variations of the inner and the outer glass cover temperatutres of the conventional basin type solar still.It can be seen that the maximum cover temperatures were reached at around 01:00 hrs and the maximum temperature difference was obtained at 11:00 hrs. In the morning hours from 08:00 to 10:00, the temperature difference is negligible. This is due to the fact that the basin water of the conventional solar still has high thermal inertia, which causes a time delay in reaching the maximum water temperature and hence the glass cover temperature. The glass cover receives the major amount of latent heat from the water vapours during the day hours. Although the ambient temperature is also high during this duration, but the heat flux from the basin water is high enough to create a significant temperature difference between the inner and the outer surface. Fig. 4 represents the hourly variation of inner and the outer glass cover temperatures for the low thermal inertia solar still. This type of solar still has a higher evaporation rate as higher absorber surface and glass cover temperatures are reached. Therefore the temperature differences in this type of still is also higher.The maximum temperature difference was observed upto $5^{\circ} \mathrm{C}$ in the low thermal inertia type still, whereas it was upto $3^{\circ} \mathrm{C}$ for the conventional solar still as can be seen from the Fig. 5 In this case also the temperature difference between the inner and outer glass surface is large whereas negligible during the morning and the evening hours. Figure 6gives an idea of the variation of the percentage difference between the inner and the outer glass cover temperatures for the two types of stills. The difference is higher for the low thermal inertia type than the conventional. For the former the maximum \% temperature difference observed was $10.2 \%$ at about 11:00 hrs, whereas for the later it was 7.14\% around 12:00 hrs. The irregular variations in between can be caused due to random wind or cloud shading effect. The thermal relation for the distillate output indicates that the distillate production depends upon the evaporative heat transfer from the water surface to the glass cover. This mode of heat and mass transfer is dependent upon the tempearture difference between the water and glass cover surfaces. Since the water vapours directly come in contact with the inner glass surface, therefore the inner surface temperature is very much significant for determining the heat transfer coefficients and the distillate production of the solar still, wether it may be conventional type or low thermal inertia type solar still.

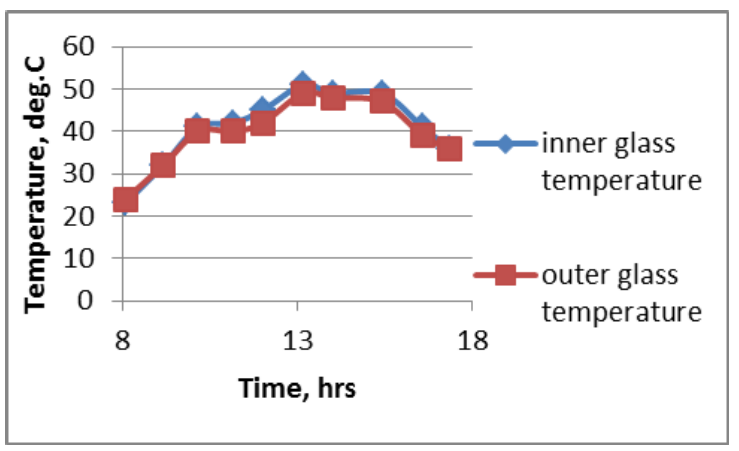

Figure 3. Glass cover temperatures of conventional solar still.

\section{Conclusion}

The study reveals a significant difference in the glass cover temperature profiles for the two different types of solar stills. In case of the low thermal inertia type solar still, the temperature difference is even more significant. However in both the cases the temperature difference between the inner and the outer glass cover surfaces is very small or even nedligible. The study can be helpful for the researchers in having a prelimnary idea of the inner and the outer glass cover temperature differences.

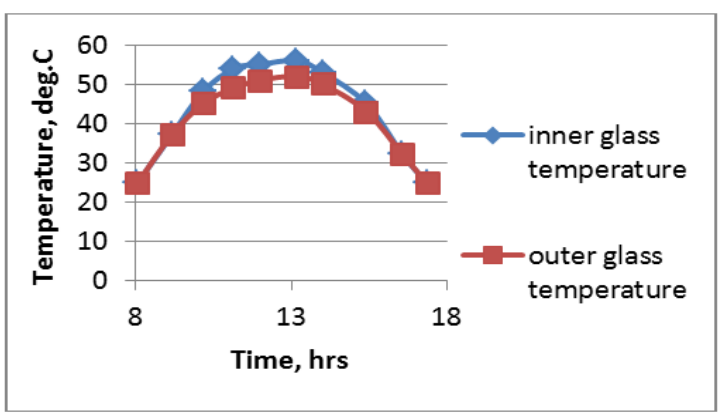

Figure 4. Glass cover temperatures of low thermal inertia solar still. 


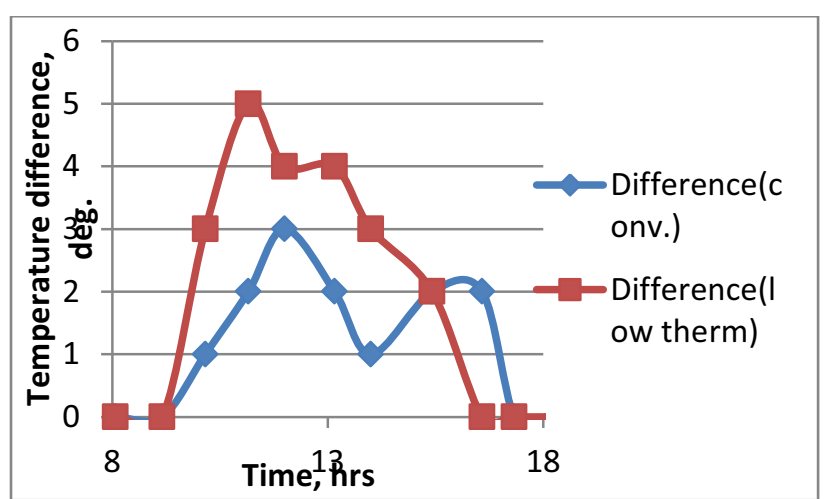

Figure 5. Difference of glass cover inner and outer temperatures.

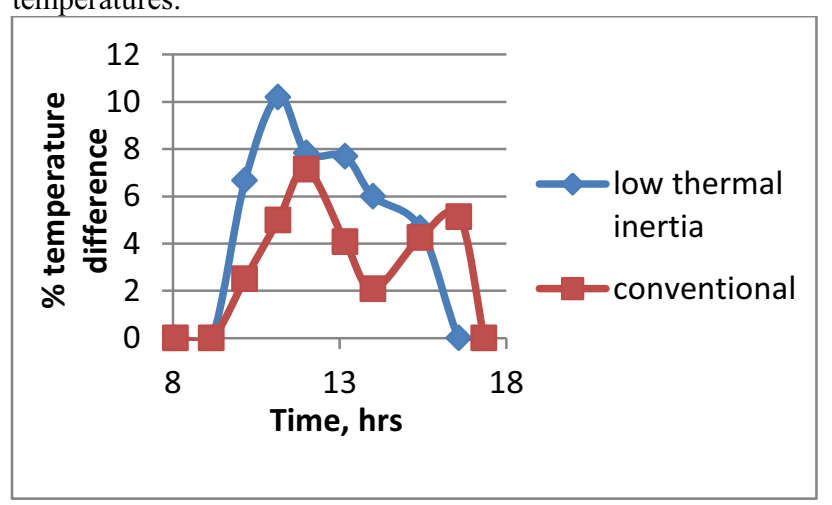

Figure 6. Percentage temperature difference for both types of solar stills.

\section{References}

1. R.V. Dunkle, International Developments in Heat Transfer, Proceedings of International Heat Transfer Conference, University of Colorado ASME, 895-902, (1961).

2. M.S. Sodha, A. Kumar, G.N. Tiwari, R.C. Tyagi, Solar Energy, 26 127-131(1981).

3. V.B. Sharma, S.C. Mullick, , J. Solar energy Trans. of ASME, 115, 231-236(1993).

4. G.N. Tiwari, J.M. Thomas, Emran Khan, Heat Rec. Syst. CHP 14, 447-455(1994).

5. A.N. Minasian, A.A. Al-Karaghouli, En.Conv. Mgmt. 36, 213-217 (1995).

6. A.A. Madani, G.M. Zaki, App.En.52, 273-281(1995).
7. A.A. El-Sebaii, J. En.Conv. Mgmt. 41, 523538(2000).

8. A. Bassam, K. Abu -Hijleh, Hamzeh M. Rababa'h, J.En.Conv. Mgmt44, 1411-1418 (2003).

9. A.A. Al-Karaghouli, W.E. Alnaser, Appl. En. 77, 317-325(2004).

10. S.K. Shukla, V.P.S. Sorayan, Ren. En.30, (5) 683699(2005).

11. S.K. Shukla, A.K Rai, Therm. Sc. 12, (3) 139152(2008).

12. Kabeel A.E., Khalil A.,Omara Z.M., Younes M.M., Desalination289, 12-20(2012).

13. Pankaj K. Srivastava, S.K. Agrawal, Desalination 311, 198-205(2013).

14. Pankaj K. Srivastava, S.K. Agrawal, Desalination 319, 73-78(2013).

15. Pankaj K. Srivastava, S.K. Agrawal, Int. J. Ren. En.Tech.5 (2), 159 - 175(2014).

16. RegilBadusha A,T V Arjunan, IJMERR. 2 (4), 74-81 (2013).

17. .S. Kumar, G,N, Tiwari, Solar Energy, 57, 459-464 (1996).

18. Abu- Hijleh, B.A.K,Desalination, 107, 235-244 (1996).

19. A.A. Sebaii, A.A. Al-Ghamdi, F.S. Al-Hazmi, Abdel S. Fidah, App. En.,86, 1187-1195 (2009).

20. V. Velmurugan, M. Gopalakrishnan, R. Raghu K. SritharEn. Con.Mgmt49, 2602-2608 (2008).

21. Hiroshi Tanaka, Desalination, 30,1-15, (2009).

22. M.S. Eldalil, M.S. Khaled, Desalination,251, 3-11, (2010).

23. M.A. Samee, U.K. Mirza, T. Majeed, N. Ahmad, Ren. Sus.En.Rev., 11, 543-549 (2007).

\section{Appendix:}

$$
\begin{aligned}
& h_{f g}=3044205.5-1679.1109 \mathrm{~T}_{\mathrm{w}}-1.14258 \mathrm{~T}_{\mathrm{w}}{ }^{2} \\
& p=165960.72 X 10^{-\left[x\left(a+b x+c x^{3}\right) / T(1+d x)\right]}
\end{aligned}
$$

Where, $x=647.27-T, a=3.2437814$,

$$
\begin{gathered}
b=5.86826 \times 10^{-3}, \quad c=1.1702379 \times 10^{-8} \\
\text { and } d=2.1878462 \times 10^{-3}
\end{gathered}
$$

